\title{
Characterization of novel nitrate reductase- deficient mutants for transgenic Dunaliella salina systems
}

\author{
L.J. Gao', Y.L. Jia ${ }^{2}$, S.K. Li ${ }^{3}$ and L.L. Qiu' ${ }^{1}$ \\ ${ }^{1}$ School of Basic Medicine, Xinxiang Medical University, Xinxiang, Henan, China \\ ${ }^{2}$ Pharmacy College, Xinxiang Medical University, Xinxiang, Henan, China \\ ${ }^{3}$ Oil Field General Hospital of Puyang City, Puyang, Henan, China \\ Corresponding author: Y.L. Jia \\ E-mail: yanlongjia@126.com
}

Genet. Mol. Res. 14 (4): 13289-13299 (2015)

Received May 13, 2015

Accepted August 11, 2015

Published October 26, 2015

DOI http://dx.doi.org/10.4238/2015.October.26.25

\begin{abstract}
The aim of the present study was to isolate and characterize novel nitrate reductase (NR)-deficient mutants, which may be useful for the transgenic manipulation of Dunaliella salina. Three NR-deficient mutants of $D$. salina, J-1, J-2, and J-3, were successfully isolated by screening for chlorate resistance after chemical mutagenesis with ethylnitrosourea. NR activity was not detected in the mutants and the expression of NR mRNA was significantly decreased. Growth analysis of $D$. salina strains grown in media containing different nitrogen sources revealed that these mutants were capable of utilizing nitrite and urea, but not nitrate as a nitrogen source, indicating that these mutants are indeed NR-deficient. Mutation analysis of NR cDNA sequences revealed that there were 11 point mutations shared by the $\mathrm{J}-1, \mathrm{~J}-2$, and $\mathrm{J}-3$ mutants. Furthermore, the results of the functional complementation experiment showed that NR activity of transformant T-1 derived from $\mathrm{J}-1$ was recovered to $48.1 \%$ of that of the wild-type $D$. salina. The findings of the present study indicate that nitrate may be used as a
\end{abstract}


selective agent rather than antibiotics or herbicides for the isolated NRdeficient mutants in future transgenic $D$. salina systems.

Key words: Dunaliella salina; Nitrate reductase; Mutant; Transgene

\section{INTRODUCTION}

Dunaliella salina (D. salina) may be a more economical and safer heterologous expression system than traditional bacterial, animal, or plant bioreactor protein expression systems (Chai et al., 2004). For the generation of transgenic $D$. salina, it is critical to construct a specific transgene selection system for determining whether the target gene has been stably integrated into the genome. Certain antibiotics and herbicides have previously been used as selective agents for $D$. salina transformed cells (Geng et al., 2003; Lu et al., 2004a, 2004b; Jiang et al., 2005; Sun et al., 2005; Walker et al., 2005a), and a bialaphos resistance (bar) gene has previously been used as a selectable marker for a $D$. salina transformation system (Lu et al., 2004b). However, biosafety concerns limit the application of these selective agents, and moreover, prior studies from our laboratory and others have shown low transformation efficiency of $D$. salina. Therefore, the development of new efficient selection systems for producing transgenic $D$. salina is a top priority.

Nitrate reductase (NR) is considered a key enzyme in the rate-limiting step of nitrogen metabolism in higher plants, fungi, and green algae (Campbell 2001). Nuclear transformation systems have been developed by introducing the NR gene (NIA1) as a selectable marker into NR-deficient mutants in Chlamydomonas (Kindle et al., 1989), Volvox (Schiedlmeier et al., 1994), and Chlorella (Dawson et al., 1997; Wang et al., 2005; Zhang et al., 2005). However, whether this selection system can be used for transgenic $D$. salina has yet to be determined.

The toxic effects of relatively innocuous chlorate are increased when it is reduced to more poisonous chlorite (and/or its decomposition products), which can be catalyzed by NR (Solomonson and Vennesland 1972; van Wijk et al., 1998). Because NR mutants with defects in the nitrogen assimilation pathway display chlorate resistance, screening for chlorate sensitivity has been successfully used for isolating mutants from several kinds of algae, such as Chlorella ellipsoidea (Wang et al., 2005) and Dunaliella viridis (Sun et al., 2006). We have previously demonstrated that wild- type $D$. salina can not grow in liquid media containing $200 \mathrm{mM}$ chlorate or on culture plates containing $100 \mathrm{mM}$ chlorate (Lu et al., 2011). Therefore, it may be possible to isolate $D$. salina mutants with defects in nitrate assimilation, which may further allow for the use of nitrate as a desirable selective agent.

Our previous work has shown that a full-length cDNA (3694 bp) of NR from $D$. salina can be heterologously expressed in E. coli as a fusion protein (Xie et al., 2007), that NR transcripts are induced by nitrate but repressed by ammonium, and that NIA1 has a strong inducible promoter that can be used to control heterologous gene expression in transgenic $D$. salina ( $\mathrm{Li}$ et al., 2007). While the isolation and characterization of NR-deficient mutants is important in the development of a novel $D$. salina transformation system using NIA1 as a selectable marker, the isolation of $D$. salina mutants with nitrate assimilation defects has not yet been explored. The purpose of the current study was to isolate and characterize NRdeficient $D$. salina mutants by screening for chlorate resistance from a mutant library generated by chemical mutagenesis with ethylnitrosourea (ENU). 


\section{MATERIAL AND METHODS}

\section{Algal strain and culture}

D. salina (UTEX-LB-1644) purchased from the Culture Collection of Algae at the University of Texas were grown in modified medium at $26^{\circ} \mathrm{C}$ with $12 \mathrm{~h}$ light/day under $60 \mu \mathrm{M}$ photon $\cdot \mathrm{m}^{-2} \cdot \mathrm{s}^{-1}$ illumination as previously described (Jia et al. 2012). When nitrite or urea was used as the sole nitrogen source, $\mathrm{KNO}_{3}$ in the medium was replaced by $5 \mathrm{mM} \mathrm{NaNO}_{2}$ or $2.5 \mathrm{mM}$ urea.

\section{Mutagenesis and screening for chlorate-resistant mutants}

Wild-type $D$. salina cells were collected at mid-exponential phase, thoroughly washed twice with nitrogen-free medium, and resuspended at approximately $2-3 \times 10^{6}$ cells $/ \mathrm{mL}$ in nitratecontaining medium. Mutagenesis was performed by adding $0.25 \mathrm{mM} E N U$, a chemical mutagen that can induce point mutations throughout the genome. Wild-type $D$. salina cells without ENU treatment were used as controls. A mutant library was obtained after 10 days of ENU incubation. ENU-mutagenized $D$. salina cells were then cultured in medium containing $200 \mathrm{mM} \mathrm{NaClO}_{3}$ for 10 days to screen for chlorate-resistant strains. Subsequently, $1 \mathrm{~mL}$ of cells $\left(1 \times 10^{6} \mathrm{cells} / \mathrm{mL}\right)$ at mid-exponential phase was concentrated to $100 \mu \mathrm{L}$ and streaked onto plates containing $100 \mathrm{mM}$ $\mathrm{NaClO}_{3}$ for further screening. Only cells with chlorate resistance were able to survive and grow into colonies. Individual green colonies were selected and transferred to $2 \mathrm{~mL}$ nitrite-containing medium, and propagated for 15-20 days. Finally, cells from each colony were centrifuged and streaked onto three different solid plates containing nitrate, nitrite, and urea as nitrogen sources. After incubation for $\sim 4$ weeks, the green colonies, which appeared on plates containing nitrite or urea but not on plates containing nitrate, were selected and transferred to $2 \mathrm{~mL}$ nitrite-containing liquid medium for further propagation. Through another round of screening, colonies that could proliferate and grow normally in medium containing nitrite or urea but not nitrate were singled out as NR-deficient mutant candidates. Putative mutant colonies selected from the above screening plates were recovered in urea-containing medium. Subsequently, the cells were transferred to a 96-well plate to isolate pure mutant clones. Specifically, cells counted and diluted to $8 \mathrm{cells} / 3 \mathrm{~mL}$ were added to the 96 -well plate at $300 \mu \mathrm{L} /$ well. The plate was incubated for $\sim 4$ weeks until colonies with a greenish color appeared, and those colonies were recovered for further characterization.

\section{Analysis of NR activity}

NR-deficient mutants of $D$. salina were identified by detecting NR activity according to methods described by Xie et al., (2007). Briefly, mutant cells grown in urea-containing medium and wild-type cells grown in nitrate-containing medium (approximately $1-2 \times 10^{6}$ cells $/ \mathrm{mL}$ ) were harvested and washed with nitrogen-free medium twice. The cells were subsequently stored at $-20^{\circ} \mathrm{C}$ for $30 \mathrm{~min}$, and then the frozen cells were rapidly homogenized in a pre-cooled mortar and pestled in $5.0 \mathrm{~mL}$ extraction buffer containing $25 \mathrm{mM}$ sodium phosphate buffer, $\mathrm{pH} 8.7 ; 10 \mathrm{mM}$ L-cysteine; and $1 \mathrm{mM}$ EDTA. Crude enzyme extracts were centrifuged at $4000 \mathrm{~g}$ for $15 \mathrm{~min}$ to remove cell debris. The enzymatic reaction was initiated by adding $0.3 \mathrm{~mL} 2 \mathrm{mg} / \mathrm{mL} \mathrm{NADH;} 0.2 \mathrm{~mL}$ $100 \mathrm{mM} \mathrm{NaNO}_{3}$; and $1.8 \mathrm{~mL} 100 \mathrm{mM}$ sodium phosphate buffer, $\mathrm{pH} 7.5$, to $0.7 \mathrm{~mL}$ crude extracts. After incubation at $26^{\circ} \mathrm{C}$ for $30 \mathrm{~min}$ in the dark, the reaction was terminated by adding $0.5 \mathrm{~mL} 3.0$ $\mathrm{M} \mathrm{HCl}$ containing $2 \%$ sulfanilamide $(\mathrm{w} / \mathrm{v})$, and $0.5 \mathrm{~mL} 0.04 \% \mathrm{~N}-(1$ - naphthyl)-ethylenediamine 
dihydrochloride $(\mathrm{w} / \mathrm{v})$. Nitrite levels were was determined from the absorbance measured at 540 $\mathrm{nm}$ by spectrophotometry and NR activity in the extracts was expressed as $\mu \mathrm{M} \mathrm{NO}_{2} \cdot\left(10^{8} \text { cells }\right)^{-1} \cdot \mathrm{h}^{-1}$.

\section{Characterization of NR mutants}

The mutants without NR activity were further characterized by chlorate-resistance growth experiments on media with different nitrogen sources. Chlorophyll content was used as an indicator for growth capacity of the mutant and wild-type cells grown in media with different nitrogen sources as described by Knobloch and Tischner (1989). Liquid media with increasing concentrations of $\mathrm{NaClO}_{3}$ (i.e. 200, 300, 400, 800, and $1600 \mathrm{mM}$ ) and solid medium containing $200 \mathrm{mM} \mathrm{NaClO}_{3}$ were used to identify whether the NR-deficient mutants had chlorate resistance.

\section{Analysis of relative gene expression of NR mRNA using qPCR}

Approximately $1 \times 10^{7}$ wild-type and NR-deficient mutant $D$. salina cells were collected by centrifugation. Total RNA was isolated using the TRIzol Reagent (Invitrogen, USA) according to manufacturer instructions, and samples were then treated with RNase-free DNase I (TaKaRa, China) to degrade residual DNA. The quality of the RNA was determined spectrophotometrically using a 260/280 nm absorbance ratio. After agarose gel electrophoresis, cDNA was synthesized with the First Strand cDNA Synthesis Kit (Sangon, China) following manufacturer instructions. All cDNA samples were either used immediately or stored at $-20^{\circ} \mathrm{C}$ until analysis. For analyzing mRNA expression of NR using $\mathrm{qPCR}$, the relative abundance $\beta$-actin mRNA was determined and used as an internal standard. The primers for NR (NR1) and $\beta$-actin were designed according to the GenBank accession numbers AY312143 and AF163669.2 respectively, and are shown in Table 1. The expression level of NR mRNA was measured by qPCR using a SYBR Premix EX Taq TM (TaKaRa, China) according to manufacturer instructions. qPCR was carried out on a GeneAmp 5700 Sequence Detection System using the 5700 Sequence Detection System software (version 1.3, Applied Biosystems, USA), which was programmed for 40 cycles consisting of $95^{\circ} \mathrm{C}$ for $30 \mathrm{~s} ; 50^{\circ} \mathrm{C}$ for $30 \mathrm{~s}$; and $72^{\circ} \mathrm{C}$ for $30 \mathrm{~s}$, and the fluorescence at the end of each cycle was monitored at $83^{\circ} \mathrm{C}$ for $5 \mathrm{~s}$. The threshold cycle $\left(\mathrm{C}_{\mathrm{T}}\right)$ value of the NR gene was normalized to the $C_{T}$ value of $\beta$-actin. Relative gene expression values of the wild-type and mutant $D$. salina cells were calculated using the comparative $C_{T}\left(2^{-\triangle \Delta C T}\right)$ method as previously described (Livak and Schmittgen 2001).

\begin{tabular}{|c|c|}
\hline Primers & Sequences (5'-3') \\
\hline \multirow[t]{2}{*}{ NR1 } & F: ATGCCCGCACTCGCCAACAA \\
\hline & R: CATTCACGG TGGAAGCAG \\
\hline \multirow[t]{2}{*}{$\beta$-actin } & F: CCATCACCATCGG CAACG \\
\hline & R: GTCGGCAATACCATGGGAACA \\
\hline \multirow[t]{2}{*}{ NR2 } & F: CCGCACTCGCCAACAACACAG \\
\hline & R: CCCTCCTTCGTGGCAATCT \\
\hline \multirow[t]{2}{*}{ NR3 } & F: AGGAGGGCTGGTGGTTCAAG \\
\hline & R: CGTTGGCTTGTGGCTGTG \\
\hline \multirow[t]{2}{*}{ NR4 } & F: CTCCGACTCCATCCTGACTG \\
\hline & R: GCTCTTTGCTGTAGCCCATC \\
\hline \multirow[t]{2}{*}{ NR5 } & F: CAAGAGGTAGAAGGGCAACA \\
\hline & R: CATTCAC GGTGGAAGCAG \\
\hline
\end{tabular}




\section{NR cDNA sequence analysis of mutants}

Total RNA from wild-type and NR-deficient mutant $D$. salina cells was isolated and reversetranscribed into cDNA as described above. To amplify the three NR cDNA fragments via PCR, three overlapping pairs of primers (NR2, NR3 and NR4) were designed according to the GenBank $D$. salina NR sequence (Table 1). PCR conditions were $95^{\circ} \mathrm{C}$ for $3 \mathrm{~min}$, followed by 30 cycles of $94^{\circ} \mathrm{C}$ for $40 \mathrm{~s} ; 59.5^{\circ} \mathrm{C}$ for $1 \mathrm{~min}$; and $74^{\circ} \mathrm{C}$ for $2 \mathrm{~min}$, and a final extension at $72^{\circ} \mathrm{C}$ for $10 \mathrm{~min}$. The resulting PCR products were purified using the Agar Gel DNA Purification Kit Ver.2.0 (TaKaRa, China) and inserted into pMD19-T vectors (TaKaRa, China), which were then used to transform JM109 competent Escherichia coli cells. To determine if sequences were correctly inserted, the resultant recombinant plasmids were digested with two restriction enzymes (EcoR I and Hind III) and analyzed by electrophoresis on agarose gels. Recombinant plasmids identified to contain the correct inserts were then sequenced. DNA from separate PCR reactions was sequenced by four different companies in order to minimize potential errors. Nucleotide sequences and deduced amino acids were aligned using the NCBI-BLAST and Clustal W programs. A search for highly conserved domains was made through the NCBI-CDD program.

\section{Functional complementation experiment}

PMDDCA-NR, a recombinant plasmid containing the wild-type NR gene driven by the duplicated carbonic anhydrase (DCA) promoter from D. salina (Lu et al., 2011) was transfected into the mutant cells using electroporation. Specifically, the mutant $D$. salina cells were collected at the mid-exponential phase by centrifugation and thoroughly washed twice with the fresh nitrogen-free medium. The cells were resuspended at $1 \times 10^{7}$ cells $/ \mathrm{mL}$ in electroporation buffer comprised of $1 \mathrm{M}$ $\mathrm{NaCl} ; 0.01 \mathrm{M} \mathrm{KCl} ; 0.01 \mathrm{M} \mathrm{CaCl}_{2}$; $0.04 \mathrm{M} \mathrm{HEPES} ; 0.4 \mathrm{M}$ mannitol; and $0.4 \mathrm{M}$ sorbitol. Subsequently, $10 \mu \mathrm{L}(1 \mu \mathrm{g})$ plasmid DNA was added to $0.4 \mathrm{~mL}$ cell suspension with gentle mixing. Prior to electroporation, the mixture was transferred to a small electroporation cuvette and chilled on ice for 5-10 min. Electroporation was performed by a Thermo CelljecT Pro Electroporation System with the following parameters: $10 \mu \mathrm{F} ; 400 \Omega$; and $1.5 \mathrm{kV}$. The electroporated cells were then transferred to $3 \mathrm{ml}$ fresh nitrate-containing medium and incubated at $26^{\circ} \mathrm{C}$ for $12 \mathrm{~h}$ in the dark. After culture for one week, the cells were streaked on nitrate-containing agar plates, and incubated for another three weeks. The transformed colonies that formed on the plates were selected and transferred to liquid medium containing nitrate and propagated for another three weeks. NR activities of the transformants were analyzed and compared with those of the mutant and wild-type cells of $D$. salina.

\section{PCR analysis of transformants}

High-quality genomic DNA was extracted from the transformants using a modified sodium dodecyl sulfate (SDS) method as previously described (Jia et al., 2012). PCR was used to detect the integration of the NR gene into the $D$. salina genome using the NR5 primer according to the DCA promoter (GenBank: AF541981) and the coding region of the NR cDNA (Table 1). PCR amplifications were performed under the following conditions: $94^{\circ} \mathrm{C}$ for $3 \mathrm{~min}$ followed by 30 cycles of $94^{\circ} \mathrm{C}$ for $30 \mathrm{~s} ; 58^{\circ} \mathrm{C}$ for $40 \mathrm{~s}$; and $72^{\circ} \mathrm{C}$ for $1 \mathrm{~min}$, and a final extension for $10 \mathrm{~min}$ at $72^{\circ} \mathrm{C}$. The PCR products were verified by electrophoresis on $1.0 \%$ agarose gels. The fragments with the expected size were recovered from the gels using the TaKaRa Agarose Gel DNA Purification Kit Ver.2.0 (TaKaRa, China), and directly sequenced. 


\section{Statistical analysis}

Statistical significance was determined with a one-way analysis of variance (ANOVA) using SPSS version 13.0 (SPSS, Chicago, USA). Summary statistics in this study were expressed as means \pm standard deviations $(M \pm S D$ ). A P value of less than 0.05 (for two-sided hypotheses) was considered statistically significant in all statistical analyses.

\section{RESULTS}

\section{Isolation and identification of NR-deficient mutants of $D$. salina}

After $D$. salina was subjected to mutagenesis with ENU followed by ten rounds of chlorateresistance screening, cells with chlorate-resistance were further screened using media containing three different nitrogen sources (nitrate, nitrite and urea). It was observed that putative mutant colonies grown on nitrite- or urea-containing plates were greenish in color similar to wild-type $D$. salina, while those on nitrate-containing plates appeared chlorotic. The green colonies selected from aforementioned screening plates were recovered individually in urea-containing medium. Finally, 42 candidate mutant colonies that were grown in nitrite- or urea- containing media were obtained and used for further characterization. As shown in Table 2, the NR activities of 9 out of the 42 candidate mutants were significantly reduced, particularly in mutants $\mathrm{J}-1, \mathrm{~J}-2$ and $\mathrm{J}-3$, whose NR activities were zero. The NR activity was consistently undetectable for at least three years in the cell extracts of stable $\mathrm{J}-1, \mathrm{~J}-2$, and $\mathrm{J}-3$ mutants by continuous monthly subculturing in fresh nitrite- or urea-containing media. The relative expression of NR mRNA was examined using qPCR. The melting curve analysis showed a specific peak at the melting temperature without the peak of the primer-dimers. NR mRNA levels were significantly decreased by 69,84 , and $77 \%$ in the $\mathrm{J}-1$, $\mathrm{J}-2$, and J-3 mutants respectively compared to wild-type $D$. salina NR mRNA levels (Figure 1).

Table 2. Comparison of NR activities between wild-type and mutant $D$. salina cells.

\begin{tabular}{lcc}
\hline Cell types & NR activity* & Relative NR activity (\%) \\
\hline Wild type & $0.4381 \pm 0.0023$ & 100 \\
m1 & $0.1723 \pm 0.0010$ & 39.33 \\
m2 & $0.1553 \pm 0.0009$ & 35.45 \\
m3 & $0.0613 \pm 0.0003$ & 13.99 \\
m4 & $0.2948 \pm 0.0105$ & 67.29 \\
m5 & $0.2515 \pm 0.0125$ & 57.41 \\
m6 & $0.1309 \pm 0.0019$ & 29.88 \\
J-1 & 0 & \\
J-2 & 0 & \\
J-3 & 0 & \\
\hline
\end{tabular}

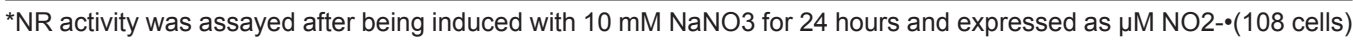
$-1 \cdot h-1$. The values (mean $\pm S D$ ) of three parallel assays are presented. The percentage of NR activity compared to that of the wild type cells is given in parentheses.

After incubation for $\sim 10$ days, the mutant cells grew vigorously and had a greenish color in nitrate-containing liquid media with different concentrations of $\mathrm{NaClO}_{3}$ compared to wild type $D$. salina cells, which became yellowish and eventually died. Furthermore, the mutant cells grew in medium containing up to $1600 \mathrm{mM} \mathrm{NaClO}_{3}$, in agreement with our previous results (Lu et al., 2011). In the present study, growth experiments of wild type and mutant $D$. salina cells were performed on solid media with various nitrogen sources. We found that colonies of the mutant cells became 
greenish on nitrite-containing plates, but no colonies appeared on the nitrate-containing plates even after 2 months of incubation (Lu et al. 2011). Additionally, wild-type cells grew better than mutant cells on solid plates containing nitrate or nitrite as the sole nitrogen source.

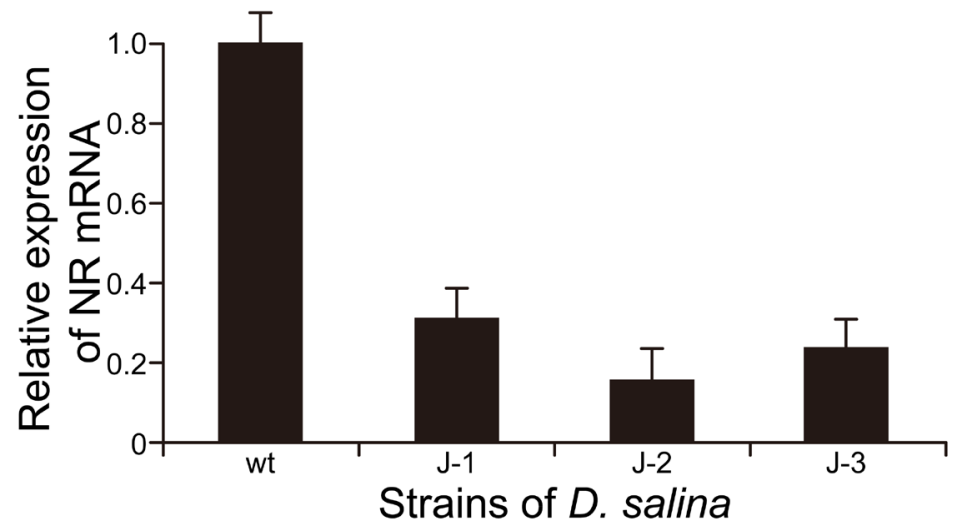

Figure 1. Changes in NR mRNA levels of $D$. salina mutants. The expression of NR mRNA in $D$. salina mutants was analyzed by qPCR, and the expression in wild-type $D$. salina cells was used as a control. The relative abundance of $\beta$-actin was used as an internal standard. The relative gene expression quantified using the $2^{-\Delta \Delta C T}$ method.

\section{Mutation analysis of NR-deficient mutants}

In order to identify the DNA mutations present in the $D$. salina mutants, NR cDNA was synthesized and sequenced. Sequencing analysis revealed that the $\mathrm{J}-1, \mathrm{~J}-2$, and $\mathrm{J}-3$ mutants had 14 , 19 , and 17 point mutations in the NR gene respectively. As shown in Table 3, of these point mutations, 11 were common in all three mutants (at nucleotide positions 425, 1056, 1847, 2119, 2290, 2358, 2569, 2593, 2595, 2611, and 2646). Importantly, 3 point mutations at positions 2119, 2290, and 2569 resulted in changes in the amino acid sequence of a highly conserved region. Additionally, it was revealed that there was a G-to-A mutation at position 1235 of mutant J-2 and a G-to-T mutation at position 1639 of mutant J-3. There was also an insertion of G, C, and T in the coding strand of the NR gene at positions 2595, 2611, and 2646 respectively in all the three mutants.

\section{Functional complementation experiment}

Twenty candidate pMDDCA-NR transformed colonies were individually selected for rescue experiments. The transformation efficiency upon rescue of the mutant phenotype by the NR-containing plasmid was $\sim 100$ transformants/ug DNA on solid nitrite-containing medium. The NR activity assay revealed that only transformant T-1 derived from mutant $\mathrm{J}-1$ had NR activity $\left[0.1866 \pm 0.0078 \mu \mathrm{M} \mathrm{NO}_{2} \cdot\left(10^{8} \text { cells }\right)^{-1} \cdot \mathrm{h}^{-1}\right]$ compared with that of wild-type cells $[0.3880 \pm 0.0151$ $\left.\mu \mathrm{M} \mathrm{NO}_{2} \cdot\left(10^{8} \text { cells }\right)^{-1} \cdot \mathrm{h}^{-1}\right]$, which was recovered to $48.1 \%$ of wild-type cell activity (Figure 2$)$. As shown in Figure 3, T-1 cells grew into the colonies with a greenish color on nitrate-containing plates, whereas mutant $\mathrm{J}-1$ cells without the NR gene did not. Furthermore, the specific expected PCR product size containing the $3^{\prime}$ end of the DCA promoter and the 5 ' end of the NR gene $(\sim$ $410 \mathrm{bp}$ ) was detected in T-1 but not in untransformed cells. Sequencing of the PCR products indicated that the amplified DNA fragment sequence was consistent with the sequences of the DCA promoter and NR gene. 
Table 3. Changes in nucleotides and amino acids of the NR gene in mutants $\mathrm{J}-1, \mathrm{~J}-2$, and $\mathrm{J}-3$.

\begin{tabular}{|c|c|c|c|c|c|c|}
\hline \multirow[t]{2}{*}{ Position } & \multicolumn{2}{|c|}{$\mathrm{J}-1$} & \multicolumn{2}{|c|}{$\mathrm{J}-2$} & \multicolumn{2}{|c|}{$\mathrm{J}-3$} \\
\hline & $\mathrm{nt}$ & aa & nt & aa & $\mathrm{Nt}$ & aa \\
\hline 218 & & & $\mathrm{~T} \rightarrow \mathrm{A}$ & $\mathrm{Val} \rightarrow \mathrm{Asp}$ & & \\
\hline 425 & $\mathrm{G} \rightarrow \mathrm{A}$ & $\mathrm{Arg} \rightarrow \mathrm{His}$ & $\mathrm{G} \rightarrow \mathrm{A}$ & $\mathrm{Arg} \rightarrow \mathrm{His}$ & $\mathrm{G} \rightarrow \mathrm{A}$ & $\mathrm{Arg} \rightarrow \mathrm{His}$ \\
\hline 498 & & & $\mathrm{C} \rightarrow \mathrm{T}$ & - & & \\
\hline 598 & & & $A \rightarrow G$ & Ser $\rightarrow$ Gly & & \\
\hline 691 & & & & & $\mathrm{~T} \rightarrow \mathrm{C}$ & Phe $\rightarrow$ Leu \\
\hline 730 & & & & & $A \rightarrow G$ & $\mathrm{Thr} \rightarrow$ Ala \\
\hline 798 & & & & & $\mathrm{G} \rightarrow \mathrm{A}$ & - \\
\hline 1056 & $\mathrm{G} \rightarrow \mathrm{A}$ & - & $\mathrm{G} \rightarrow \mathrm{A}$ & - & $\mathrm{G} \rightarrow \mathrm{A}$ & - \\
\hline 1235 & & & $\mathrm{G} \rightarrow \mathrm{A}$ & $\operatorname{Trp} \rightarrow \boldsymbol{\Lambda}$ & & \\
\hline 1323 & & & $\mathrm{G} \rightarrow \mathrm{A}$ & - & & \\
\hline 1367 & $\mathrm{~T} \rightarrow \mathrm{G}$ & - & $\mathrm{T} \rightarrow \mathrm{G}$ & - & & \\
\hline 1639 & & & & & $\mathrm{G} \rightarrow \mathrm{T}$ & $\mathrm{Glu} \rightarrow \boldsymbol{\Lambda}$ \\
\hline 1781 & & & $A \rightarrow G$ & Asp $\rightarrow$ Gly & & \\
\hline 1847 & $\mathrm{C} \rightarrow \mathrm{T}$ & $\mathrm{Ala} \rightarrow \mathrm{Val}$ & $\mathrm{C} \rightarrow \mathrm{T}$ & $\mathrm{Ala} \rightarrow \mathrm{Val}$ & $\mathrm{C} \rightarrow \mathrm{T}$ & $\mathrm{Ala} \rightarrow \mathrm{Val}$ \\
\hline 1937 & & & $\mathrm{G} \rightarrow \mathrm{A}$ & Arg $\rightarrow$ Lys & & \\
\hline 1993 & & & & & $\mathrm{~A} \rightarrow \mathrm{T}$ & $\mathrm{lle} \rightarrow$ Phe \\
\hline 2032 & $\mathrm{G} \rightarrow \mathrm{A}$ & Gly $\rightarrow$ Ser & & & & \\
\hline 2119 & $A \rightarrow G$ & Lys $\rightarrow$ Glu & $A \rightarrow G$ & Lys $\rightarrow$ Glu & $A \rightarrow G$ & Lys $\rightarrow$ Glu \\
\hline 2139 & & & & & $\mathrm{~T} \rightarrow \mathrm{C}$ & - \\
\hline 2290 & $A \rightarrow G$ & Met $\rightarrow$ Val & $A \rightarrow G$ & Met $\rightarrow$ Val & $A \rightarrow G$ & Met $\rightarrow$ Val \\
\hline 2300 & $A \rightarrow G$ & Lys $\rightarrow$ Arg & & & & \\
\hline 2358 & $\mathrm{C} \rightarrow \mathrm{A}$ & -- & $C \rightarrow A$ & - & $\mathrm{C} \rightarrow \mathrm{A}$ & - \\
\hline 2569 & $\mathrm{~T} \rightarrow \mathrm{A}$ & Leu $\rightarrow$ Met & $\mathrm{T} \rightarrow \mathrm{A}$ & Leu $\rightarrow$ Met & $\mathrm{T} \rightarrow \mathrm{A}$ & Leu $\rightarrow$ Met \\
\hline 2593 & $\mathrm{G} \rightarrow \mathrm{C}$ & Ala $\rightarrow$ Pro & $\mathrm{G} \rightarrow \mathrm{C}$ & $\mathrm{Ala} \rightarrow$ Pro & $\mathrm{G} \rightarrow \mathrm{C}$ & $\mathrm{Ala} \rightarrow$ Pro \\
\hline 2595 & $\rightarrow \mathrm{G}$ & * & $\rightarrow \mathrm{G}$ & * & $\rightarrow \mathrm{G}$ & * \\
\hline 2611 & $\rightarrow \mathrm{C}$ & * & $\rightarrow \mathrm{C}$ & * & $\rightarrow \mathrm{C}$ & * \\
\hline 2646 & $\rightarrow T$ & * & $\rightarrow T$ & * & $\rightarrow T$ & * \\
\hline
\end{tabular}

$\mathrm{Nt}$, nucleotides; aa, amino acids; ${ }^{*}$, frame-shift mutation; -, null mutation; $\boldsymbol{\Lambda}$, stop codon.

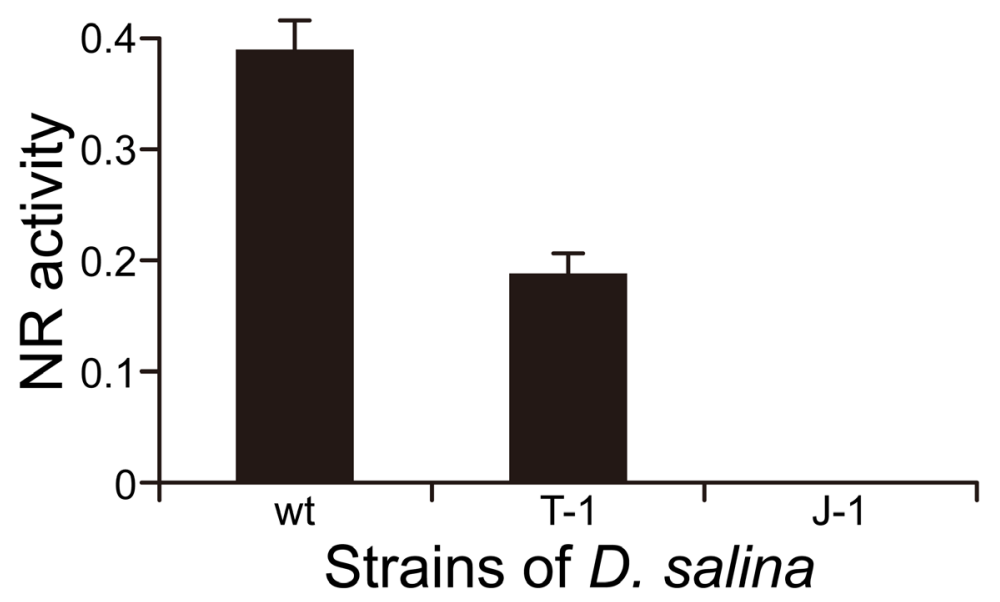

Figure 2. NR activity of $D$. salina transformant T-1 with the pMDDCA-NR vector. The NR activity of wild-type and mutant J-1 D. salina cells were used as positive and negative controls respectively. NR activity was expressed as $\mu \mathrm{M}$ NO2 $\cdot(108$ cells $)-1 \cdot h-1$. 


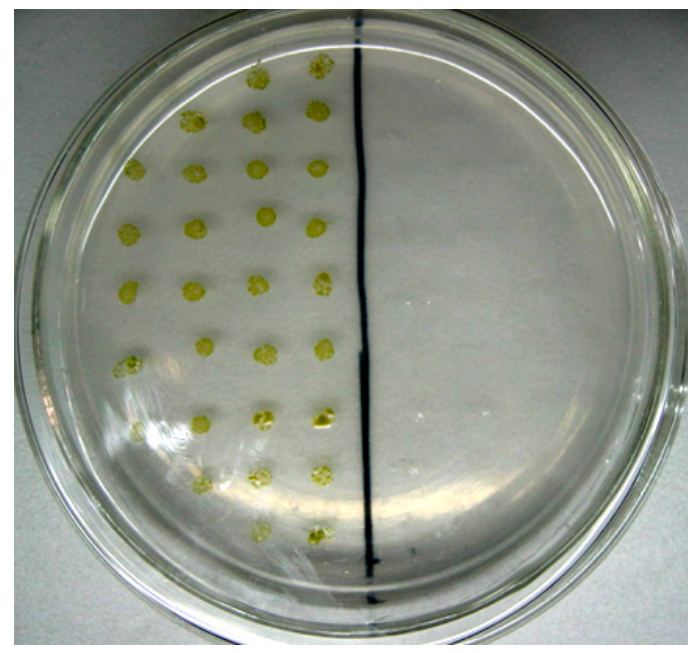

Figure 3. Characterization of transformant T-1. After T-1 cells with plasmid harboring the NR gene and the NR mutant $\mathrm{J}-1$ without the NR gene were incubated simultaneously on the nitrate-containing plate for $\sim 4$ weeks, the former grew into the colonies with a greenish color (Left), but not the latter (Right).

\section{DISCUSSION}

It has been demonstrated that $D$. salina has a significant commercial value as a source of $\beta$-carotene and glycerol. Recently, the use of $D$. salina as new typical bioreactor is becoming more attractive in producing biologically active proteins (Chai et al., 2004). Several different selectable markers have been used for the screening of Dunaliella transformants by our laboratory and others including the chloramphenicol acetyltransferase (CAT) gene under the control of the SV40 promoter (Geng et al., 2003), the bar gene under the control of the duplicated carbonic anhydrase 1 (DCA1) promoter of $D$. salina (Lu et al., 2004a), and the ble gene under the control of the Chlamydomonas RBCS2 promoter or the D. tertiolecta RBCS1 promoter (Sun et al., 2005; Walker et al., 2005a). However, the use of antibiotic or herbicide selective agents could be harmful to the environment if used in transgenic Dunaliella production systems (Walker et al., 2005b). Here, we characterized a novel nutrient-deficient transformation system in which nitrate is used as a selective agent, which offers several inherent advantages over antibiotics and herbicides including high biosafety, easy manipulation, and low cost.

In the present study, we optimized the chlorate-resistance selection conditions for screening NR-deficient mutants. We further demonstrated that mutagenesis induced by a low concentration of ENU $(0.25 \mathrm{mM})$ over a short time period (10 days) resulted in relatively mild point mutations that had an impact on the function of the genes of interest but not on the survival of the cells. Microscopic observation revealed that there were no significant differences in cell morphology, activity, and growth rates between wild-type and NR-deficient mutant $D$. salina cells, indicating that there were no critical mutations affecting the growth of the NR-deficient mutants. Through ENU mutagenesis and subsequent screening for chlorate-resistance, 42 candidate mutant colonies were obtained, of which three mutants $\mathrm{J}-1, \mathrm{~J}-2$, and $\mathrm{J}-3$ had no NR activity suggesting full NR deficiency. Additionally, the results of the functional complementation experiment and NR activity assay showed that a 410 bp of specific fragment of the pMDDCA-NR plasmid was amplified in transformant T-1 originally derived from $\mathrm{J}-1$, and its NR activity was recovered to $48.1 \%$ of wild-type $D$. salina, demonstrating that the wild-type NR gene could rescue the mutant phenotype. Based on the above findings, the 
isolated mutants may be useful for selection of stable $D$. salina transformants using nitrate as a desirable selective agent.

In photosynthetic eukaryotes, NR is an enzyme complex containing flavin adenine dinucleotide (FAD), b-type heme, and molybdopterin cofactor (MoCo) as prosthetic groups acting as redox centers for the transfer of electrons from NAD(P)H to nitrate (Campbell 1999). Previous study have shown that NR from $D$. salina shares common structural features with NR from higher plants and other green algae including the Mo-MPT domain with the nitrate-reducing site between amino acids 82 and 311, the heme-Fe domain between amino acids 543 and 616, and the FAD domain between amino acids 661 and 757 (Xie et al., 2007). Mutation analysis of the sequences herein suggests that three kinds of critical mutations led to a loss of all NR catalytic activity including property changes of some amino acid residues, stop codon introduction, and frameshift mutations. For example, 3 of the 11 NR mutations shared by the three mutants at positions 2119, 2290 and 2569 had amino acid changes in a highly conserved region including the cytochrome $b 5$ domains of sulfite oxidase and microsomal cytochrome b5 (Cyt b557/heme) form. These mutations might affect the function of the Cyt b557/heme domain of NR resulting in the loss of NR activity involving this domain. We also deduced that the loss of NR activity in mutants $\mathrm{J}-2$ and J-3 may have resulted from the G-to-A mutation at position 1235 of mutant J-2 and G-to-T mutation at position 1639 of mutant $\mathrm{J}-3$, in which the codons for tryptophan or glutamic acid residues normally present were converted to stop codons leading to truncated proteins (deletion of 488 and 353 residues of NR in mutants $\mathrm{J}-2$ and $\mathrm{J}-3$ respectively). Additionally, the insertion mutations of $\mathrm{G}, \mathrm{C}$, and $\mathrm{T}$ (at positions 2595, 2611 and 2646) resulting in frameshifts in NR mRNA were found in all three mutants, and 19 amino acid residues were incorporated at the C-terminal region of the truncated NR protein due to these frameshift mutations. Therefore, we believe that the point and insertion mutations resulted in erroneous NR protein sequences, which failed to fold into functional domains. This is a likely reason for why the mutant cells were incapable of using nitrate as a source of nitrogen. However, further investigation should be performed to determine whether frameshift mutations are a critical factor to loss of NR activity.

In summary, three NR-deficient mutants were successfully isolated from $D$. salina, which may be used for the transgenic manipulation of $D$. salina, and may also be useful tools for the study of NR in nitrogen assimilation/metabolism in $D$. salina.

\section{Conflicts of interest}

The authors declare no conflict of interest.

\section{ACKNOWLEDGMENTS}

Research supported by the grants from the Hi-Tech Research and Development Program of China (\#2002AA628050), and International Science and Technology Cooperation Program of the Ministry of Science and Technology of China (\#2007DFA01240).

\section{REFERENCES}

Campbell WH (1999). Nitrate reductase structure, function and regulation: bridging the gap between biochemistry and physiology. Annu. Rev. Plant Physiol. Plant Mol. Biol. 50: 277-303.

Campbell WH (2001). Structure and function of eukaryotic NAD(P)H: nitrate reductase. Cell. Mol. Life Sci. 58: $194-204$.

Chai Y, Wang T, and Xue L (2004). Recent Progress in a New Bioreactor: Dunaliella salina. J. China Biotechnol. 24 : 30-33. 
Dawson HN, Burlingame R and Cannons AC (1997). Stable transformation of Chlorella: rescue of nitrate reductase-deficient mutants with the nitrate reductase gene. Curr. Microbiol. 35: 356-362.

Geng D, Wang Y, Wang P, Li W, et al. (2003). Stable expression of hepatitis B surface antigen in Dunaliella salina (Chlorophyta). J. App. Phycol. 15: 451-456.

Jia Y, Xue L, Li J and Liu H (2010). Isolation and proteomic analysis of the halotolerant alga Dunaliella salina flagella using shotgun strategy. Mol. Biol. Rep. 37: 711-716.

Jia Y, Li S, Allen G, Feng S, et al. (2012). A novel glyceraldehyde- 3-phosphate dehydrogenase (GAPDH) promoter for expressing transgenes in the halotolerant alga Dunaliella salina. Curr. Microbiol. 64: 506-513.

Jiang G, Lu Y, Niu X, and Xue L (2005). The actin gene promoter-driven bar as a dominant selectable marker for nuclear transformation of Dunaliella salina. J. Genet. Genomics 32: 424-433.

Kindle KL, Schnell RA, Fernandez E and Lefebvre PA (1989). Stable nuclear transformation of Chlamydomonas using the Chlamydomonas gene for nitrate reductase. J. Cell. Biol. 109: 2589-2601.

Knobloch O and Tischner R (1989). Characterization of nitrate reductase of deficient mutants of Chlorella sorokiniana. Plant Physiol. 89: 786-791.

Li J, Xue L, Yan H, Wang L, et al. (2007). The nitrate reductase gene-switch: a system for regulated expression in transformed cells of Dunaliella salina. Gene 403: 132-142.

Livak KJ and Schmittgen TD (2001). Analysis of relative gene expression data using real-time quantitative PCR and the 2 (-Delta Delta C(T)) method. Methods 25: 402-408.

Lu Y, Jiang G, Niu X, Hou G, et al. (2004a). Cloning and functional analyses of promoters of two carbonic anhydrase genes from Dunaliella salina. J. Genet. Genomics. 31: 1157-1166.

Lu Y, Xie H, Niu X, Jiang G, et al. (2004b). Transfer of bar gene to Dunaliella salina by microprojectile delivery and detection of transgenic alga. J. Zhengzhou Uni. (Med. Version) 39: 31-35.

Lu Y, Li J, Li S, Yan H, et al. (2011). A duplicated carbonic anhydrase 1 (DCA1) promoter mediates the nitrate reductase geneswitch of Dunaliella salina. J. Appl. Phycol. 23: 673-680.

Schiedlmeier B, Schmitt R, Muller W, Kirk MM, et al. (1994). Nuclear transformation of Volvox carteri. Proc. Natl. Acad. Sci. USA 91: 5080-5084.

Solomonson LP and Vennesland B (1972). Nitrate reductase and chlorate toxicity in Chlorella vulgaris Beijerink. Plant Physiol. 50: 421-424.

Sun Y, Yang Z, Gao X, Li Q, et al. (2005). Expression of foreign gene in Dunaliella by electroporation. Mol. Biotechnol. 30: 185-192.

Sun Y, Gao X, Li Q, Zhang Q, et al. (2006). Functional complementation of a nitrate reductase defective mutant of a green alga Dunaliella viridis by introducing the nitrate reductase gene. Gene 377: 140-149.

Van Wijk DJ, Kroon SG and Garttener-Arends IC (1998). Toxicity of chlorate and chlorite to selected species of algae, bacteria, and fungi. Ecotoxicol. Environ. Saf. 40:206-211.

Walker TL, Becker DK, Dale JL and Collet C (2005a). Towards the development of a transformation system for Dunaliella tertiolecta. J. Appl. Phycol. 17: 363-368.

Walker TL, Purton S, Becker DK and Collet C (2005b). Microalgae as bioreactors. Plant Cell Rep. 24: 629-641.

Wang Y, Chen Y, Zhang X, Wang P, et al. (2005). Isolation and characterization of a nitrate reductase deficient mutant of Chlorella ellipsoidea (Chlorophyta). J. Appl. Phycol. 17: 281-286.

Xie H, Xu PY, Jia YL, Li J, et al. (2007). Cloning and heterologous expression of nitrate reductase genes from Dunaliella salina. J. Appl. Phycol. 19: 497-504.

Zhang XY, Wang P, Zhao SM, Li X, et al. (2006). Expression of rabbit neutrophile peptide-1 in nitrate reductase-deficient mutant of Chlorella ellipsoidea. Yi Chuan 28: 1580-1584. 